\title{
Zollinger-Ellison syndrome
}

INSERM

\section{Source}

INSERM. (1999). Orphanet: an online rare disease and orphan drug data base. ZollingerEllison syndrome. ORPHA:913

Zollinger-Ellison syndrome (ZES) is characterized by severe peptic disease (ulcers/esophageal disease) caused by hypergastrinemia secondary to a gastrinoma resulting in increased gastric acid secretion. 